\title{
Tazim Jamal and Mike Robinson (eds.) (2009). SAGE Handbook of Tourism Studies. SAGE Publications 716 pp. ISBN 978-1-4129-2397-2
}

\author{
Reviewed by Miroslava Dimitrova
}

Received: 25/02/10

\begin{abstract}
Department of Tourism, International University College, 3 Bulgaria str., 9300 Dobrich, Bulgaria; tel: +359 58655 630; e-mail: miroslava.dimitrova@vumk.eu
\end{abstract}

(c) 2010 International University College. All rights reserved

Citation: Tazim Jamal and Mike Robinson (eds.) (2009). SAGE Handbook of Tourism Studies. SAGE Publications 716 pp. ISBN 978-1-4129-2397-2. Reviewed by Miroslava Dimitrova European Journal of Tourism Research 3(1), pp.101-102

SAGE Handbook of Tourism Studies presents an ambitious endeavor to encompass the multifaceted nature of tourism studies in one single volume. It aims to reflect wide-ranging conceptual approaches to the subject of tourism giving a special attention to recently emerging themes and issues.

The editors are both academic professionals and possess a strong background in tourism study which reflects the quality of the selected materials included in The Handbook.

The volume is divided into three main sections which are: "Approaches to Tourism studies", "Key Topics in Tourism" and "Critical Issues and Emerging Perspectives". There are thirty-nine chapters included in The Handbook. Each chapter is a complete unit and reflects a unique feature of tourism study.

The chapters included in the first section cover wide range of disciplinary approaches such as sociology and anthropology of tourism, tourism history and geography, economics and politics of tourism.
The second section pinpoints key topics in tourism. The discussed themes in different chapters cover multiple issues such as: spirituality, religion and their relation to tourism; theme parks; architecture and urban planning; heritage conservation; sustainable tourism and ecotourism; rural tourism; safety and security; transportation; destination marketing and management, etc.

The third section outlines the recently emerging perspectives in tourism studies, among which are events management; tourism and postcolonialism; thanatourism; ethical perspectives; global tourism business operations; gender studies and languaging.

Each chapter presents a deep analysis of the stated problem which is elaborated in details. Strong attention is paid to the relationship between tourism and culture which is evident in almost every discussed subject (from sociology and anthropology of tourism to such innovative approaches as gender studies). The qualitative methods of analysis are preferred over quantitative. The topics included are of a great interest to anybody 
who has aspiration to reach highest level of achievement in the field of tourism study, thus making The Handbook a "must" for every academic worker and tourism expert.

Tourism and its global impact on the economy, policy, natural and social environment is beyond any doubt. According to the World Travel \& Tourism Council statistics (WTTC, 2010), tourism sector contributes for $9,4 \%$ of the World GDP, employs near $7,6 \%$ of the total population and accounts for almost $11 \%$ of the world export. Tourism sector is one of the biggest and most important industries in the world. This fact alone could justify the need of more profound and versatile study of its complex nature. The SAGE Handbook of Tourism Studies is much more than an "over-intellectualization of a seemingly frivolous leisure practice", it is a knowledge base of almost everything concerning the somewhat elusive nature of tourism.

One of the biggest challenges before The Handbook is to clarify the scope of tourism studies and to draw a hypothetic boundary between topics considered for inclusion and those which stay outside. In this case it is comprehensible that even in the pursuit of thoroughness some themes are deliberately missed or overlooked. It is surprising however that core topics such as the intermediaries in tourism (tour operators and travel agents) are not discussed.

Taking into consideration the fact that this volume represents a collection of many authors' work, it is understandable that there is little or no coherence between the styles of writing, methodology and the approaches in general applied in the different chapters. Also it could explain the presence of overlapping of themes and quotations that are evident in some cases.

In Conclusion, The SAGE Handbook of Tourism Studies is a really useful and helpful book that gives a comprehensive and thorough overview of all aspects of tourism studies. The book is addressed to a wide range of people, including students, academics and professionals in tourism. It could be used either as a textbook or as an indispensable source of references. The noted above omissions and limitations could not by any means underestimate its obvious virtues. This book is a valuable acquisition to the tourism section of any library.

\section{References:}

WTTC (2010) Tourism impact data and forecasts. URL: http://www.wttc.org 